\title{
AS PARCERIAS PÚBLICO-PRIVADAS NO ESTADO DE SÃO PAULO: A CONTRIBUIÇÃO AO PROCESSO DE DESCENTRALIZAÇÃO DA ADMINISTRAÇÃO PÚBLICA
}

\author{
THE PUBLIC-PRIVATE PARTNERSHIP IN SÃO PAULO STATE: THE CONTRIBUTION TO \\ THE PROCESS OF PUBLIC ADMINISTRATION DECENTRALIZATION
}

Leandro Capergiani Moreira

Mestrando do Programa de Pós-Graduação em Administração - PPGA USCS

Luis Paulo Bresciani

Professor Doutor do Programa de Pós-Graduação em Administração - PPGA USCS

Sirlei Tereza Pitteri Vieira

Doutoranda do Programa de Pós-Graduação em Administração - PPGA USCS

Geison Cantarelli Muniz de Queiroz

Mestrando do Programa de Pós-Graduação em Administração - PPGA USCS
Recebido em: 24/08/2012 Aceito em: 21/12/2012

\section{RESUMO}

Este artigo busca analisar como as Parcerias Público-Privadas (PPPs) podem contribuir no processo de descentralização administrativa do Estado em complemento aos modelos tradicionais de concessões e privatizações, e apresentar um estudo empírico sobre a concessão patrocinada da Linha 4 do Metrô de São Paulo. Para tanto foram realizadas, além do resgate do processo de descentralização da administração pública no Brasil, a análise de documentos oficiais referentes à PPP da Linha 4 do Metrô paulistano e entrevistas com gestores públicos envolvidos com as PPPs no Estado de São Paulo. O resultado dos estudos demonstrou que as PPPs proporcionam novas possibilidades de parcerias entre os setores público e privado, sendo um interessante instrumento de política pública para viabilizar investimentos em infraestrutura e contribuir com a maior eficiência do Estado brasileiro.

Palavras-chave: descentralização; parceria público-privada; linha 4 do Metrô.

\section{ABSTRACT}

This paper aims to analyze how the Public Private Partnerships (PPPs) can contribute to the process of State administrative decentralization in addition to traditional concessions and privatizations, and to present an empirical study about the sponsored concession of the São Paulo Subway Line 4. For that we discussed the decentralization of public administration in Brazil, and also analyzed relevant official documents relating to the PPP for São Paulo Subway Line 4; interviews with PPP public managers were done too. The study shows that PPPs provide new opportunities for partnerships between public and private sectors, being an interesting instrument of public politics to increase infrastructure investments and to contribute with a greater efficiency of the Brazilian state.

Keywords: decentralization; public-private partnership; Sao Paulo Subway Line 4.

Endereços dos autores:

Leandro Capergiani Moreira

leandrocapergiani@uscs.edu.br

Sirlei Tereza Pitteri Vieira

sirleipitteri@uscs.edu.br

\author{
Luis Paulo Bresciani \\ lpbresciani@uscs.edu.br \\ Geison Cantarelli Muniz de Queiroz \\ Geison.queiroz@ibest.com.br
}




\section{INTRODUÇÃO}

Até o final da década de 1960 os Estados nacionais foram os impulsionadores do desenvolvimento econômico e social, mas de acordo com Bresser-Pereira (1998), a partir da década de 1970 esse modelo entra em crise e passa a ser o grande motivo da queda no ritmo de crescimento dos países e no aumento da inflação em diversos países do mundo. Com base na experiência internacional Bresser Pereira (1998), ressalta que no Brasil, a crise financeira dos anos 1980, ocasionada pelo aumento da inflação e do endividamento público, reduziu de modo significativo a capacidade de realizar investimentos em infraestrutura, dando início ao processo da reforma pública gerencial, que envolveu quatro temas principais:

a) $\mathrm{A}$ delimitação do tamanho do Estado;

b) Definição do papel regulador do Estado;

c) A recuperação da governança;

d) Aumento da Governabilidade.

No caso brasileiro esta discussão deu origem a um processo de privatizações e concessões de alguns setores onde preponderava o monopólio do Estado brasileiro. Contudo, Pinto (2005) lembra que privatizações e concessões tradicionais só são possíveis quando o projeto é autossustentável economicamente, ou seja, a operação do serviço é capaz de remunerar o investimento realizado pelo parceiro privado.

Assim, o que fazer com os projetos de infraestrutura de interesse público que não são economicamente viáveis para a iniciativa privada, como a construção de ferrovias ou estradas com pouco tráfego? Pinto (2005) nos dá uma noção da importância desses serviços:

Embora não sejam rentáveis para os particulares, projetos desse tipo interessam ao Estado porque seu retorno econômico e social excede a receita que as empresas privadas podem extrair deles diretamente. Ou seja, esses projetos apresentam grandes externalidades positivas. Uma estrada de tráfego pouco intenso facilita $o$ desenvolvimento de regiões isoladas, ainda que esse valor intangível não possa ser apropriado a ninguém. De forma semelhante, um serviço de coleta de lixo eficiente é essencial para a saúde de toda a população, não somente para os seus usuários diretos (PINTO, 2005, p.4).

É nesse contexto de restrição orçamentária e déficit de infraestrutura que surge a Parceria Público-Privada (PPP), um instrumento de política pública capaz de viabilizar projetos que seriam economicamente inviáveis para a iniciativa privada e muito caros para o Estado prover devido a grande restrição orçamentária.

Pastori (2007) salienta que particularmente para a realidade brasileira, a PPP também é indicada para projetos de infraestrutura com pouca ou nenhuma sustentabilidade financeira, ou seja, inviáveis para a operação única e exclusiva da iniciativa privada e muito caro para o governo.

Assim, o objetivo deste artigo é identificar como as Parcerias PúblicoPrivadas (PPPs) podem contribuir no processo de descentralização administrativa do Estado em complemento aos modelos tradicionais de concessões e privatizações, apresentando-se a experiência da concessão patrocinada da Linha 4 - do Metrô de São Paulo.

A metodologia para a elaboração do presente estudo constituiu-se do levantamento documentos oficiais pertinentes e de entrevistas com gestores públicos de alto nível hierárquico da Companhia Paulista de Trens Metropolitanos (CPTM), da Companhia do Metropolitano de São Paulo (Metro), da Secretaria de Transportes Metropolitanos do Estado de São Paulo (STM) e, por fim, da 
Secretária de Planejamento e Desenvolvimento Regional do Estado de São Paulo. Para efeitos de deste estudo, os entrevistados serão denominados como Gestor A, Gestor B, Gestor C e Gestor D, respectivamente.

Estruturado em quatro seções para além dessa introdução, o artigo aborda o processo de descentralização administrativa do Estado brasileiro, traz um breve histórico do surgimento e principais características das PPPs no Brasil, e apresenta um estudo empírico sobre a parceria realizada para a construção da Linha 4 do Metrô, na cidade de São Paulo.

\section{O PROCESSO \\ DESCENTRALIZAÇÃO ADMINISTRATIVA NO BRASIL}

DE

De acordo com Feriancic (2011) a descentralização, como forma de aumentar a eficiência estatal, é um conceito consolidado entre os princípios do Estado brasileiro. Já em 1967 o Decreto Lei 200 foi um marco em relação ao assunto:

Art 6. As atividades da Administração Federal obedecerão aos seguintes princípios fundamentais:

I - Planejamento

II - Coordenação

III - Descentralização

IV - Delegação de Competência

V - Controle

[...]

Art. 10. A execução das atividades da Administração Federal deverá ser amplamente descentralizada.

$\S 1^{\circ}$ A descentralização será posta em prática em três planos principais:

a) dentro dos quadros da Administração Federal, distinguindo-se claramente o nível de direção de execução;

b) da Administração Federal para as unidades federadas, quando estejam devidamente aparelhadas e mediante convênio; c) da administração Federal para a órbita privada, mediante contratos de concessão.

(BRASIL, 1967)

Contudo, é importante lembrar que este processo de diminuição do tamanho do Estado teve como marco a publicação do Decreto 83.740, de 18 de Julho de 1979, que depois de um longo processo de estatização reverteu o contexto e instituiu o Programa Nacional de Desburocratização, que tinha como objetivo simplificar o funcionamento da administração pública federal. Porém, conforme Saurin e Pereira (1998) este foi o primeiro de muitos planos e legislações: no ano de 1998 o Programa Nacional de Desestatização, já pautado pela falência do Estado, tinha entre seus objetivos proceder à execução indireta de serviços públicos, por meio de concessões e permissões.

Carvalho (2001) classifica o processo de privatização e concessões em três fases: a primeira fase caracteriza-se pela privatização de empresas que tinham pertencido originalmente à iniciativa privada, durante o período de 1981 e 1989 foram "reprivatizadas" principalmente as empresas que apresentavam elevado grau de endividamento junto ao setor público. $\mathrm{O}$ objetivo principal dessa fase foi $o$ saneamento financeiro do BNDES.

A segunda fase, de acordo com Carvalho (2001) teve início no ano de 1990 com o Programa Nacional de Desestatização. Nessa fase o Estado estava redefinindo seu papel deixando de atuar em setores como indústria, infraestrutura e serviços, e focando suas atividades na regulação e físcalização de serviços públicos essenciais. Essa fase estendeu-se até o final de 2004 e abrangeu a privatização de empresas de grande porte e historicamente estatais, principalmente dos setores de siderurgia, petroquímica e fertilizantes.

A terceira e última fase iniciou-se em 1995 e caracterizou-se pela concessão de serviços públicos à iniciativa privada com o 
advento da aprovação da Lei de Concessões em fevereiro de 1995. Para Carvalho (2001), nesta fase preponderou a concessão de empresas de infraestrutura e também de serviços públicos. Os setores de telecomunicações, energia elétrica e transporte foram os mais atingidos.

As privatizações, mesmo apresentando efeitos positivos, foram amplamente criticadas devido ao baixo valor presente. Para Savi (2006), surge aí a necessidade de se criar uma nova estrutura de cooperação entre setor público e o privado, direcionada principalmente para o setor de infraestrutura, que necessita de altos investimentos e retorno de longo prazo.

As parcerias entre o setor público e privado, de acordo Borges (2007), ganharam folego com a aplicação adaptada do modelo inglês de Project Finance Initiative - PFI. Na década de 1990, outros modelos, como as privatizações e concessões, foram utilizados em grande escala, mas as possibilidades para aqueles tipos de parcerias são limitadas. A implantação do novo modelo de parceria, as chamadas PPPs, considerou as características políticas e o contexto econômico de cada país.

\section{AS PARCERIAS PÚBLICO- PRIVADAS - PPP'S}

As PPPs, segundo Shinohara e Savoia (2008), surgiram na Europa, especificamente no Reino Unido com o nome de PFI - Private Finance Iniciative. Neste sentido, Pastori (2007) cita que a maioria dos autores, quando se refere à moderna origem das PPPs, utiliza-se do exemplo britânico como precursor dessa modalidade. Porém o mesmo autor ao tratar do modelo britânico esclarece que no PFI o setor público mantém a responsabilidade pela prestação de parte dos serviços, o que não acontece no modelo brasileiro. De acordo com os autores o objetivo principal do PFI é viabilizar projetos por meio do financiamento privado, pois a capacidade de implantá-los com recursos públicos estava extremamente reduzida.

O mesmo autor cita que em 1997 esse programa foi ampliado e rebatizado para Public-Private Partnership (PPP), com o objetivo de mudar a forma de contratação de serviços públicos, passando da compra de ativos para a compra de serviços. Para Pastori (2007), as PPPs são modalidades de contratação onde o governo e as empresas dividem o investimento $\mathrm{e}$ os riscos na construção e operação de obras e serviços públicos. As PPPs podem ser utilizadas com alternativa para viabilizar investimentos em infraestrutura em momentos de restrição orçamentária do governo, com a vantagem adicional de, em geral, apresentar redução dos custos das obras e aumento da eficiência.

Para Azevedo (2008), as PPPs combinam os pontos fortes dos setores público e privado, partilhando os riscos, em resposta às falhas de mercado $e$ minimizando as falhas do Estado, assumindo uma nova via onde Estado e mercado caminham juntos na busca da eficiência na utilização de recursos públicos, mas sem esquecer-se da remuneração dos parceiros privados.

Nesse sentido, Saraiva (2008), considerando que a iniciativa privada tem melhores incentivos para operar serviços, em especial de infraestrutura que exigem grandes investimentos, lembra que diversos países passaram a utilizar a iniciativa privada para prover obras e serviços que eram, historicamente, prerrogativas do governo.

A justificativa para a criação das PPPs foi o crescente déficit público aliado à ideia de potencializar sinergias e economias, aproveitando a experiência da iniciativa privada para implementar projetos de infraestrutura necessários para o 
desenvolvimento territorial. Azevedo (2008) indica que as parcerias surgem como consequência não só de reorientar e redimensionar o setor público, mas também de aproximar a iniciativa privada do setor público tendo uma base de cooperação duradoura para a provisão de investimentos em infraestrutura e na oferta de serviços públicos.

De acordo com Saraiva (2008), as PPPs já estavam em uso em vários países desenvolvidos como uma opção dos governos para aumentar sua eficiência. Nesses países há a possibilidade de realizar os investimentos com recursos públicos ou a alternativa de desenvolver uma PPP e, a decisão ótima é aquela que oferece os melhores resultados para o contribuinte e a sociedade, contudo, Pasin e Borges (2003) salientam que as PPPs possuem variantes distintas, de acordo com o país onde é aplicada de modo a atender a legislação e a sua cultura local.

Para Azevedo (2008), ao equilibrarem o triplo vértice composto de provisão, financiamento e prestação de infraestruturas e serviços públicos, as PPPs passaram a serem encaradas como parte integrante das soluções governamentais, enquanto instrumentos de politicas públicas capazes de apoiar a redução dos significativos déficits de infraestrutura encontrados na maioria dos países.

Em termos de sua aplicação, os investimentos em infraestrutura são, devido às necessidades de altos investimentos, os mais beneficiados com a modelagem de PPP; de fato, em meados da década passada, o setor de transportes se destacava em termos de maior atenção em 12 países analisados pelo BNDES (2007), com parcerias específicas na construção de estradas e ferrovias.

\subsection{As Parcerias Público-Privadas no Brasil}

$\mathrm{Na}$ literatura internacional, qualquer articulação ou transferência de responsabilidade entre o poder público e a iniciativa privada é considerada como PPP, a exemplo das sociedades de economia mista, joint ventures, franquias, terceirização, privatizações e as concessões em geral. Já no Brasil, são consideradas PPPs apenas as parcerias regidas pela Lei 11.079 de 2004.

Quando se analisam as experiências internacionais com PPP's, percebe-se que o termo "parceria público-privada" se aplica a uma série de parcerias que variam dentro de um espectro de transferências de responsabilidades e propriedade dos ativos envolvidos. Analisando-se o texto no contexto brasileiro, nota-se que este se refere a um tipo particular de parceria que, à primeira vista, assemelha-se a uma concessão tradicional (SHINOHARA E SAVOIA, 2008, p.42).

Considerando essa dificuldade de conceituação do termo Parceria PúblicoPrivada, a Secretaria de Planejamento do Governo Federal solicita atenção e define de modo amplo as "parcerias da administração", conforme destacado abaixo: [...] O termo PPP encontrado na literatura internacional, portanto, deve ser lido com cautela e encontra um conceito similar no Brasil que denominamos "Parcerias da Administração", conceito amplo, não definido legalmente, que englobaria institutos como privatização, permissão, concessões em geral, franquia, terceirização, convênios, termos de parceria, contratos de gestão e outros. (Site da Secretaria de Planejamento, acesso em 14/12/2011).

Colocadas as ressalvas sobre as denominações e conceitos usados na experiência brasileira frente ao amplo significado do termo PPP na literatura internacional, cabe passarmos ao movimento mais recente sobre o tema. De fato, no ano de 2004 foi promulgada pelo governo 
federal a Lei $\mathrm{n}^{\circ} 11.079$ que cria dois novos tipos de concessão de serviços públicos: a concessão patrocinada e a administrativa. Na primeira, a população usuária do serviço público oferecido arca com parte ou mesmo com toda a remuneração do parceiro privado. Já na segunda, o parceiro público remunera diretamente o parceiro privado pelo investimento realizado.

De acordo com o Gestor D, a legislação brasileira considerou as experiências internacionais em sua elaboração, e tentou evitar falhas identificadas nas experiências internacionais estabelecendo, de forma explícita critérios de distribuição de riscos e também estabelecendo definições rígidas quanto aos projetos que podem ser viabilizados através de PPPs.

A Lei Federal 11079 define em seu artigo $2^{\circ}$ a parceria público-privada como um "contrato administrativo de concessão, na modalidade patrocinada ou administrativa". Assim, criaram-se dois novos modelos de concessão que diferem das concessões comuns reguladas pela Lei 8.987/1995:

- Concessão Patrocinada: Definida do artigo $2^{\circ}$ inciso primeiro da Lei Federal 11.079/2004, como a concessão de serviços ou obras públicas, similares às concessões criadas pela Lei 8.987/1995, porém envolvendo, adicionalmente à tarifa cobrada dos usuários, uma contraprestação pecuniária do parceiro público.

Concessão Administrativa:

Definida do art. $2^{\circ}$ inciso segundo, da Lei Federal 11.079/2004, como o contrato de prestação de serviços onde a administração pública seja usuária direta ou indireta, mesmo que envolva a execução de obras ou fornecimento de bens e instalações.

$\mathrm{Na}$ concessão administrativa, conforme Shinohara e Savoia (2008), a concessionária não é remunerada diretamente pelos usuários do serviço ou bem público, mas sim pelo governo ou órgão ligado a ele.

A Lei Federal 11.079/2004 também instituiu diretrizes que devem ser observadas na contratação de PPPs:

a) eficiência no cumprimento das missões do Estado e no emprego dos recursos da sociedade;

b) respeito aos interesses e direitos dos destinatários dos serviços e dos entes privados incumbidos de sua execução;

c) não delegação das funções de regulação, do exercício do poder de polícia e de outras atividades exclusivas do Estado;

d) responsabilidade fiscal na celebração e execução de parcerias;

e) transparência dos procedimentos e das decisões;

f) repartição objetiva de riscos entre as partes;

g) sustentabilidade financeira e vantagens socioeconômicas dos projetos de parceria.

Nas PPPs o prazo de vigência dos contratos deve ser compatível com a amortização dos investimentos realizados, e, não deve ser inferior a cinco anos ou superior a trinta e cinco anos. Outra diferença significativa é a obrigatoriedade da constituição de uma SPE (Sociedade de Propósito Especifica) para gerir exclusivamente o objeto da parceria antes da assinatura do contrato. De acordo com Souza (2008), a justificativa para a exigência de criação da SPE é, por parte do poder público, a facilitação do controle exercido sobre o cumprimento do contrato e também porque não é conveniente misturar recursos públicos e privados, destinados uns e outros a finalidades diversas.

Uma das grandes dificuldades para implantar as PPPs é atrair a iniciativa privada para projetos que envolvem diversos tipos de riscos. Segundo Azevedo Neto 
(2008) os riscos de uma PPP podem ser resumidos nos seguintes:

a) riscos de receita: envolvendo variação da demanda, valor de remuneração, competição eficiente, atraso no início da operação, inadimplência na contrapartida pública;

b) riscos atrelados a custos: envolvendo falhas de projeto, risco tributário, variação de preços de insumos;

c) riscos de financiamento: cambial, política monetária, aversão do investidor;

d) riscos de autoridade: risco regulatório, risco político, risco judiciário, interfaces federativas;

e) riscos externos: ambiental, movimentos de consumidores, movimentos sindicais.

Para Pinto (2005), nas PPPs regidas pela Lei 11.079/2004 o Estado contrata uma empresa particular para realizar uma obra e depois prestar um serviço e, em contrapartida, o Estado paga uma remuneração que, complementa ou substitui a receita obtida com a prestação do serviço.

As PPP exigem a participação de um ente público compartilhando os custos, em geral, através da subvenção econômica ou subsídio de tarifa dos serviços ofertados. Nos projetos de transporte de passageiros sobre trilhos, conforme Pastori (2007) compete tradicionalmente ao poder concedente realizar os investimento em infraestrutura de via permanente e ao parceiro privado os investimentos em material rodante.

Pode-se considerar que as PPP são arranjos contratuais, entre o governo e o setor privado, para a provisão de bens e serviços tradicionalmente providos pelo setor público. Outras definições mencionam a divisão de prêmio e risco entre setor público e setor privado, pois, para que haja um envolvimento voluntário do setor privado na realização de investimentos, há a necessidade do estabelecimento do prêmio
(SARAIVA, 2008).

Para Pastori (2007) a PPP brasileira é um contrato de prestação e serviços de longo prazo entre o ente público e o privado, podendo os serviços ser prestados diretamente à população ou ao governo,

Pinto (2005) salienta que as PPPs permitem que o Estado delegue ao particular não só a execução da obra, mas também a elaboração do projeto. Isso possibilita o alcance de ganhos de eficiência superiores nas Parcerias Público-Privadas, em relação às obras públicas realizadas nos moldes convencionais.

Vale ainda notar que os projetos de infraestrutura indicados para a modelagem baseada em PPP podem ser percebidos como economicamente deficitários e com isso existe a dificuldade de atrair investidores, mas Pastori (2007) aponta também como característica da PPP a capacidade de estimular $\mathrm{O}$ investidor privado para efetivação de investimentos públicos, considerando que permite o compartilhamento de riscos entre os parceiros, para assim atingir o equilíbrio econômico e financeiro do projeto.

Para Azevedo (2008), esta capacidade de atrair o investidor privado torna a PPP um instrumento de política pública que permite manter, em tempos de restrição orçamentária, um volume de investimento adequado e a modernização dos serviços públicos utilizando o financiamento privado em troca da devida partilha dos riscos do projeto.

Em relação à restrição orçamentária, Oliveira (2006) acrescenta ser necessário reconhecer as fragilidades do Estado em promover, de forma plena, os investimentos para atender a demanda de serviços públicos e de infraestrutura existentes. Contudo, o eventual interesse de governos na modelagem de PPPs vai além do benefício financeiro, pois dentre os objetivos poderão estar, conforme Pastori 
(2007), a aderência do projeto ao plano governamental e também interesses políticos. Desse modo, enquanto a iniciativa privada busca um adequado retorno financeiro para o investimento, o ente público procura viabilizar um dado projeto buscando a melhor solução de custos e benefícios.

\subsection{A Situação das PPPs no Estado de São Paulo}

Em relação às Parcerias PúblicoPrivadas, sua aplicação no Estado de São Paulo está relacionada ao Programa Estadual de Desestatização (PED), que tem como um de seus dispositivos o estímulo à participação da iniciativa privada em projetos de interesse e caráter público.

Nessa perspectiva, o Governo Estadual regulamenta as PPPs através da Lei 11.688/2004 que institui o Programa de Parcerias Público-Privadas do Estado de São Paulo. Atualmente, o Governo do Estado de São Paulo possuí uma das maiores carteiras de projeto de PPPs do Brasil e, mesmo com as dificuldades causadas pelo seu ineditismo, alguns projetos já foram implantados nesta modelagem e outros estão em estudo e elaboração.

Em relação a estas dificuldades, o Gestor A salienta que o Governo Estadual segue apreendendo a trabalhar com este modelo de concessão:

A PPP é uma ferramenta que parece interessante, mas que precisa de um tempo de gestão para se conseguir colocá-la em marcha e fazer com que ela aconteça. Eu acredito que a principal questão que se coloca ao se trabalhar com essa Legislação é a própria interpretação da Lei, pois existem algumas dificuldades e, dentro da própria instância do Governo há diferentes interpretações a respeito de como colocar em marcha essa Lei e praticar de fato a PPP.

Porém, mesmo com as dificuldades apontadas, diversos são os projetos em andamento. De acordo com a relação de projetos monitorados pela Secretaria de Planejamento e Desenvolvimento Regional ao final de 2011, o Estado de São Paulo contava então com três Parcerias PúblicoPrivadas efetivamente contratadas, contemplando a PPP da Linha 4 (Amarela) do Metrô, e outros dois contratos de caráter metropolitano.

$\mathrm{O}$ primeiro deles se refere ao Sistema Produtor do Alto Tietê (ETA Taiaçupeba), que trata da ampliação da capacidade de fornecimento de água tratada na Região Metropolitana de São Paulo e implantação de sistema de tratamento de lodo, com a construção de $17,7 \mathrm{~km}$ de adutoras e quatro reservatórios somando capacidade total de $70.000 \mathrm{~m} 3$.

O segundo contrato de PPP de âmbito metropolitano diz respeito ao novo sistema de Trens da Linha 8 (Diamante) da CPTM, que contempla a modernização e manutenção do material rodante que opera na referida linha férrea, interligando a estação da Luz ao município de Itapevi, também na Região Metropolitana de São Paulo.

Também ao final de 2011, verificase a existência de dois projetos de Parcerias Público-Privadas já com modelagem aprovada, relacionados ao transporte público. O primeiro se refere ao Sistema de Arrecadação Centralizada do Bilhete Integrado, com o objetivo de gestão da cobrança das tarifas públicas dos serviços de transporte metropolitano de passageiros no Estado de São Paulo. O segundo projeto com modelagem aprovada diz respeito ao Sistema Integrado Metropolitano da Região Metropolitana da Baixada Santista (SIM), com o objetivo de implantação e operação de 39 linhas de ônibus e um corredor para 
Veículos Leves sobre Trilhos (VLT).

Por fim, para além das Parcerias

Público-Privadas contratadas ou aprovadas, encontravam-se em estudo ao final de 2011 os projetos relacionados à implantação do Expresso ABC (alteração do sistema de transporte ferroviário para a região do Grande ABC), O Corredor Litoral Norte ( $3^{\mathrm{a}}$ Etapa do Programa de Concessões Rodoviárias do Estado), as Travessias Litorâneas, o Sistema Prisional (incluindo o Sistema de Esgotamento Sanitário em Presídios), investimentos na Habitação, a implantação das Salas de Aula Interativas, e a rede de informação denominada Intragov.

\section{A PPP DA LINHA 4 (AMARELA) DO SISTEMA METROVIARIO}

A referida PPP, na modalidade de concessão patrocinada, foi assinada em novembro de 2006 entre o Governo do Estado de São Paulo, na qualidade de poder concedente, e a sociedade de propósito especifico concessionária da Linha 4 do Metrô de São Paulo, empresa denominada ViaQuatro. A contratação teve ainda como intervenientes a Companhia do Metropolitano de São Paulo (Metrô) e a Companhia Paulista de Trens Metropolitanos (CPTM). Além das partes já citadas, assinaram o contrato na condição de anuentes a Companhia Paulista de Parcerias (CPP) e a Empresa Metropolitana de Transportes Urbanos de São Paulo (EMTU).

Esta foi efetivamente a primeira PPP assinada no Brasil, e de acordo com o Gestor B, isto ocorreu devido ao fato de que o Governo do Estado de São Paulo já estar trabalhando na modelagem das parcerias utilizando como base a lei das concessões onerosas, juntamente com a Lei Estadual 11.688/2004, que regulamenta as PPPs no Estado de São Paulo, e que havia sido publicada seis meses antes da nova legislação federal sobre o tema.
Nós acompanhávamos, já naquele momento, a tramitação da Lei Federal, e tínhamos alguns princípios, parâmetros e condições que estavam já sendo discutidas e negociadas no Congresso Nacional, mas estávamos trabalhando sem os detalhes do que depois foi aprovado na Lei. Então, trabalhamos, na verdade, muito mais com o que a gente tinha na concessão onerosa, a chamada concessão tradicional, com os princípios desse modelo, porque as informações que nós tínhamos é que a Lei 11.079 traria algo adicional a 8.987, mas não a mudaria, e foi justamente o que aconteceu.

O objetivo da parceira é a concessão para a exploração dos serviços de transporte de passageiros na chamada Linha 4 (Amarela) do Metrô de São Paulo, no trecho compreendido entre a Luz e a futura estação de Taboão da Serra.

O projeto está dividido em três fases consecutivas; sendo que a primeira fase consiste na operação dos trens entre seis estações (Butantã, Pinheiros, Faria Lima, Paulista, Republica e Luz), e na implantação do pátio de manutenção de Vila Sônia. Os investimentos realizados por parte do parceiro privado contemplam o fornecimento de material rodante (quatorze trens metroviários com seis vagões), a implantação do sistema de sinalização nas estações, nas vias permanentes e pátio de manutenção, os subsistemas de comunicação móvel de voz e dados do sistema de telecomunicações, o sistema de controle de pátio da Vila Sônia, e o sistema de supervisão e controle centralizado. Além dos investimentos o parceiro privado deverá realizar os serviços de operação e manutenção do trecho em operação.

Nesta fase os investimentos realizados pelo poder concedente consistem na construção da infraestrutura e na implantação dos sistemas relacionados aos túneis e via permanente, construção das seis 
estações de operação inicial, construção da estrutura das futuras estações Fradique Coutinho, Oscar Freire e Higienópolis, e partes especificas do pátio de manutenção da Vila Sônia. Também são de responsabilidade do Estado os investimentos relacionados com energia e telecomunicações, sistema de controle de arrecadação e de passageiros, e equipamentos auxiliares do pátio de Vila Sonia.

A operação da fase I iniciou-se em maio de 2010 com a inauguração das estações Paulista e Faria Lima e no decorrer de 2011 as outras quatro estações entraram em operação.

A fase II considera a operação da Linha 4 - Amarela com as onze estações previstas, Vila Sônia, Morumbi, Butantã, Pinheiros, Faria Lima, Fradique Coutinho, Oscar Freire, Paulista, Higienópolis, Republica e Luz, em pleno funcionamento e, também, a operação por ônibus no trecho entre a estação Vila Sõnia e a região do Taboão da Serra.

Os investimentos do parceiro privado na fase II são a) fornecimento de material rodante - quinze trens metroviários de seis carros cada; b) implantação do sistema de sinalização; c) Subsistemas de comunicação móvel de voz e dados do sistema de telecomunicações; d) sistema de controle de pátio Vila Sônia; e) sistema de supervisão e controle centralizado.

Além dos investimentos citados, o parceiro privado deverá operar o serviço de transporte metroviário da Linha 4 (Amarela) entre as 11 estações e operar no trecho Vila Sônia - Taboão da Serra, através de veículos sobre pneus. Ressalta-se que a operação do trecho que ocorrerá através de pneus não terá cobrança adicional de tarifa.

$\mathrm{Na}$ fase II os investimentos realizados pelo poder concedente consistem na a) conclusão das estações Fradique
Coutinho, Oscar Freire e Higienópolis; b) conclusão do Pátio de manutenção Vila Sônia, terminal de ônibus urbano e a extensão do túnel e da via permanente até Vila Sônia; c) construção das estações Vila Sônia e Morumbi.

Além das obras acima o Estado concluirá o fornecimento e implantação dos sistemas de energia, telecomunicação, controle local, equipamentos auxiliares, subsistema de transmissão digital do sistema de telecomunicações e sistema de controle de arrecadação e de passageiros.

A aquisição de todos os outros materiais e equipamentos necessários para a operação da Linha 4 - Amarela serão de responsabilidade exclusiva do parceiro privado.

Já a fase III do contrato de PPP prevê a operação sobre trilhos do trecho compreendido entre as estações Vila Sônia e Taboão da Serra. As condições de operação desta fase deverão ser definidas no decorrer do contrato.

O contrato de parceria condiciona o inicio da fase II com uma série de investimentos em material rodante na Linha 9 - Esmeralda da CPTM de forma a garantir a integração dos usuários com a Linha 4 Amarela na estação Pinheiros.

A remuneração do parceiro privado ocorrerá, por tratar-se de concessão patrocinada, de duas formas, a primeira é através da receita tarifaria do sistema metroferroviário, que deve ser centralizada em uma câmara de compensação financeira do sistema metroferroviário e do transporte sobre pneus geridos pela São Paulo Transportes - SPTRANS, e a segunda através de contraprestação pecuniária paga diretamente pelo Estado de São Paulo.

Cabe ressaltar que a receita tarifária devida ao parceiro privado é calculada pela quantidade de passageiros transportados e pelo cumprimento dos indicadores de 
qualidade dos serviços prestados e de manutenção.

Em relação à divisão dos riscos citadas nos estudos analisados, a PPP da Linha 4 identificou e apropriou os riscos considerando qual dos membros da parceria possuía melhores condições para gerir e minimizar o risco. Os principais riscos identificados foram o risco de demanda, o processo de mitigação realizou a divisão do risco entre os parceiros, assim, algumas faixas de tolerância foram elaboradas. Em casos de variação da demanda em $10 \%$, para mais ou para menos, o risco é todo do parceiro privado. Para variações entre $10 \%$ e $20 \%$, para mais ou para menos, deverá ser aplicada uma fórmula de compartilhe $\mathrm{o}$ risco entre os parceiros público e privado. Para as variações entre $20 \%$ e $40 \%$, para mais ou para menos, será aplicada outra forma de compartilhamento do risco. Nos casos extremos, em que a variação for superior a $40 \%$, deverá ser realizado o reequilíbrio econômico e financeiro do contrato de concessão. Por fim, o mecanismo de mitigação do risco de demanda só poderá ser utilizado seis meses após o inicio de operação da fase I.

Outros riscos identificados foram o atraso, por parte do Governo do Estado, na implantação das obras de sua responsabilidade, não realização dos investimentos na Linha 9 - Esmeralda da CPTM e concorrência das linhas de ônibus intermunicipais com a linha 4.

Cabe ressaltar que o Estado de São Paulo, mesmo concedendo a operação da Linha 4 - Amarela para a iniciativa privada, mantem sua função de regulador $e$ fiscalizador do serviço prestado pelo parceiro privado. Assim, o Estado continua responsável pelo serviço prestado, inclusive o contrato de PPP prevê que, caso o serviço prestado não esteja em conformidade com os padrões indicados pelo Estado, este pode penalizar o parceiro privado e até mesmo cancelar o contrato de concessão.

Para o Gestor C, a implantação da Linha 4 - Amarela representou diversos avanços no aprendizado sobre as PPPs e, também, sobre a operação de transportes metroviários. Como mencionado anteriormente, esse é o primeiro projeto de parceria do Brasil e, em relação ao transporte metroviário a operação da Linha 4 pela iniciativa privada capacitou mais uma empresa a realizar este serviço. Atualmente, no Estado de São Paulo existem duas empresas com experiência neste tipo de transporte em São Paulo, a Companhia do Metropolitano - Metro e a Concessionária ViaQuatro que obteve esta experiência através desta PPP.

\section{CONCLUSÃO}

Atualmente, os governos têm utilizado diferentes mecanismos de Articulações Público-Privadas - APP's para fornecer ao cidadão diversos tipos de serviços públicos que, tradicionalmente, eram oferecidos pelo Estado provedor do bem-estar social.

Contudo o processo de redefinição do Estado através de parceiras com a iniciativa privada ficou limitado uma vez que muitos setores e serviços que poderiam ser delegados para a inciativa privada eram inviáveis financeiramente. A publicação da Lei $\mathrm{n}^{\circ} 11.079 / 2004$, que regulamentou as PPPs nas modalidades de concessão administrativa e patrocinada, tendo como principal característica a possibilidade de divisão dos investimentos necessários para implantação de determinado projeto entre o parceiro público e o privado, contribui para equacionar a referida parceria.

Nesse sentido, o governo busca aproveitar a potencial agilidade do parceiro privado para implantar projetos e também superar um dos grandes problemas da gestão pública, a falta de recursos orçamentários. Assim, investimentos que seriam inviáveis 
para os parceiros isoladamente tornam-se viáveis econômica e socialmente.

Analisando a experiência do Estado de São Paulo percebemos que poucos projetos foram implantados utilizando esta nova possibilidade de parceria, porém percebe-se um interesse do Governo pelos diversos projetos em fases de modelagem e licitação.

Para o Gestor C, da Secretaria Estadual de Transportes Metropolitanos, a contribuição que as PPPs proporcionaram ainda são pequenas, mas a experiência da Linha 4 tem proporcionado, na visão dos gestores, a preservação dos padrões de qualidade indicados pelo Estado, configurando um avanço no sistema metroferroviário paulista. A maior contribuição que a PPP da Linha 4 do Metro apresenta foi a possibilidade de implantar uma nova linha sem comprometer a qualidade do serviço prestado nas demais linhas operadas pela Companhia do Metropolitano . A pergunta que pode surgir é o motivo pelo qual não foram utilizados os modelos de privatização ou concessão;

o argumento colocado pelos gestores é que a construção e operação da linha não proporcionam retorno financeiro suficiente para atrair o parceiro privado, condição básica para os modelos citados.

Assim, a parceria para a concessão da Linha 4 só foi possível devido ao modelo adotado, o que demonstra o seu potencial para contribuir com o processo de descentralização de serviços públicos e a consequente reorganização do Estado.

Por fim, vale ressaltar a perspectiva representada pelo Gestor B, de que embora existam muitas criticas aos modelos de parcerias entre o público e o privado existentes atualmente, elas são importantes para a população, pois o Estado tem que se concentrar em setores essenciais e quando se delega atividades complementares todos tem a possibilidade de receber uma parcela dos benefícios, principalmente a população.

Assim, a PPP surge para auxiliar no processo de descentralização e, também, como um mecanismo de política pública relevante para promover o desenvolvimento territorial e regional, pois proporciona projetos complexos que demandam altos investimentos e que socialmente proporcionam externalidades positivas para a metrópole e para a população. 
AlVarenga, J. E. de. Parcerias PúblicoPrivadas - comentários à lei brasileira. São Paulo: M. A. Pontes, 2005.

AZEVEDO NETO, Floriano de (Org.). Reajuste e Revisão nas Parcerias PúblicoPrivadas Revisitando o Risco nos Contratos de Delegação. In: SOUZA, Mariana Campos de. Parceria Público-Privada: Aspectos Jurídicos Relevantes. São Paulo: Quartier Latin, 2008. Cap. 4, p. 53-78.

AZEVEDO, Maria Eduarda. As Parcerias Público Privadas: Instrumentos de uma Nova Governação Pública. 2008. 659 f. Tese (Doutorado) - Curso de Ciências Jurídicoeconômicas, Departamento de Faculdade de Direito, Universidade de Lisboa, Lisboa, 2008.

BORGES, L. F. X. Uma visão da aplicação da Parceria Público-Privada no mundo em 2006. Revista do BNDES, Rio de Janeiro, v.14, n.27, p.323-330, Jun.2007.

BRASIL. Decreto Lei $\mathrm{n}^{\circ} 200$, de 25 de fevereiro de 1967.

BRASIL. Decreto 83.740, de 18 de julho de 1979.

BRASIL. Lei $\mathrm{n}^{\circ} 11.079$, de 30 de dezembro de 2004.

BRASIL. Lei $n^{\circ} 8.987$, de 13 de fevereiro de 1995.

BRESSER-PEREIRA, Luiz Carlos. A Reforma do Estado dos Anos 90: Lógica e Mecanismos de Controle. Lua Nova: Revista de Cultura e Política, São Paulo, n. 45, p.49-95, 1998.
CARVAlHO, Marco Antônio de Sousa. Privatização: Aspectos Fiscais e Dívida Pública. 2001. 156 f. Dissertação (Mestrado) - Curso de Economia, Escola de Pósgraduação em Economia - EPGE, Fundação Getúlio Vargas, Rio de Janeiro, 2001.

FERIANCIC, Gabriel. Elegibilidade e estruturação de concessões de serviços e obras de transporte com o instituto das parcerias público-privadas. 2011. 267 p. f. Tese (Doutorado) - Curso Engenharia de Transporte, Escola Politécnica da Universidade de São Paulo, São Paulo, 2011. OLIVEIRA, Paulo Henrique Mainier de.

Parceria Público-Privada: Novo Mecanismo de Financiamento e AutoSustentabilidade dos Transportes Metroferroviários. 2006. 41 f. Monografia (Concurso de Monografia) - Companhia Brasileira de Transportes Urbanos, Rio de Janeiro, 2006.

PASIN, Jorge Antônio Bozoto; BORGES, Luiz Ferreira Xavier. A Nova Definição de Parceria Público-Privada e sua Aplicabilidade na Gestão de Infraestrutura Pública. Revista do BNDES, Rio de Janeiro, v. 10, n. 20, p.173-196, 2003.

PASTORI, Antonio. As PPPs como Ferramenta para Viabilizar Projetos de InfraEstrutura de Transporte Ferroviário sobre trilhos. Revista do BNDES, Rio de Janeiro, v. 14, n. 28, p.93-120, dez. 2007. 


\section{REFERÊNCIAS}

PINTO, Marcos Barbosa. A Função Econômica das PPP's. Revista Eletrônica de Direito Administrativo, Salvador, n. 2, 2005. SARAIVA, Eduardo Cesar Gomes. Projetos de Infraestrutura Pública: Risco, Incerteza e Incentivos. 2008. 108 f. Tese (Doutorado) Curso de Economia, Departamento de Escola de Pós-graduação em Economia, Fundação Getúlio Vargas, Rio de Janeiro, 2008.

SAURIN, Valter; PEREIRA, Breno Augusto D. O Programa Nacional de Desestatização: aspectos relevantes da política de privatização. Revista de Ciências da Administração, Ano 1, n. 0, ago. 1998. Departamento de Ciências da Administração da UFSC. Florianópolis, SC: 1998.

SAVI, Erika Monteiro de Souza e. Parcerias Público-Privadas (PPPs) na Irlanda e no Chile: alternativa de alavancagem para o desenvolvimento em infraestrutura no cenário brasileiro. 2007. 145 f. Dissertação (Mestrado) - Curso de Engenharia de Produção, Departamento de Escola de Engenharia de São Carlos, Universidade de São Paulo, São Carlos, 2006.

SHINOHARA, Daniel Yoshio; SAVOIA, José Roberto Ferreira. Parcerias PúblicoPrivadas no Brasil. Brasil: Manole, 2008. SOUZA, Mariana Campos de. As Parceiras Público-Privadas à luz do artigo 175 da Constituição Federal. In: SOUZA, Mariana Campos de (Org.). Parceria Público-Privada: Aspectos Jurídicos Relevantes. São Paulo: Quartier Latin, 2008. Cap. 8, p. 149-164. 
